\title{
TEACHING STUDENTS WITH DISABILITIES AT THE COLLEGE LEVEL
}

\author{
Rebekah Dyer, Grand Canyon University
}

\begin{abstract}
The number of students with disabilities who attend college is increasing, but many of them are not completing their degree program. Many students with disabilities are not socially prepared to attend college. They may struggle with developing relationships with peers and faculty, which leads to a feeling of not being supported. There are a variety of perceptions regarding individuals with disabilities held by peers and faculty that can negatively impact students with disabilities in college. Students with disabilities do have a legal right to receive accommodations at the college level; however, many students are not aware of those rights or choose not to pursue them. Colleges and universities and faculty need to be a support system for students with disabilities and need to be proactive in being informed about the law and the types of accommodations they can provide. Students with disabilities can be successful in college if everyone works together to set them up for success.

Keywords: perceptions, Americans with disabilities act, accommodations, disabilities, university, college

\section{INTRODUCTION}

Students with disabilities in kindergarten through 12th grade (and through the age of 21) receive special education services through the Individuals with Disabilities Education Act (IDEA) (Individuals with Disabilities, 2004). This law provides students with disabilities with the proper supports, accommodations, and modifications, to be successful in the general curriculum. Once a student with a disability graduates from high school, they are no longer eligible for the components of IDEA. Students with disabilities have the right to reasonable and effective accommodations under the Americans with Disabilities Act (ADA) (Americans with Disabilities, 1990). Students with disabilities are ensured equal access to educational programs through ADA by eliminating policies and practices that discriminate against individuals with disabilities (Barnard-Brak, Davis, Tate, \& Sulak, 2009).

According to the National Center for Education Statistics (NCES), 11\% of undergraduates in the

2011-12 school year reported having a disability (National Center for Educational Statistics, 2015). The number of students with disabilities who began college for the first time as full-time students increased significantly between 1978 and 1994 . The National Council on Disability reported that $17 \%$ of students in college were identified as having a disability in 2000 (Barnard-Brak et al., 2009). The number of students with disabilities participating in postsecondary education is increasing; however, fewer students with disabilities complete their degree than those without disabilities (Fleming, Plotner \& Oertle, 2017). Higher education is beneficial for many individuals, but it can make an even bigger impact on the lives of individuals with disabilities. The number of individuals who live at or below the poverty level, receive cash assistance, food stamps, or live in public housing, increases when disability is a factor (Barnard-Brak et al., 2009). The Task Force on Postsecondary Education and Disabilities determined the most effective component that leads to financial independence is


attaining higher education (VESID, 2000).

According to Fleming et al. (2017), the factors related to the success of students with disabilities in college can include relationships with and perceptions of peers and faculty and knowledge of accommodations. Supports for students with disabilities that negate negative attitudes from faculty and increase the awareness of disability law can provide better outcomes for students with disabilities who attend college (Fleming et al., 2017).

\section{RELATIONSHIPS}

Transition to the college environment presents a variety of challenges for all students, and this appears to be increased for students with disabilities. Social isolation and higher levels of loneliness are reported by students with disabilities in college (Herts, Wallis, \& Maslow, 2014). The transition to the college atmosphere for students with disabilities can be made more manageable through peer networks (Herts et al., 2014). As with many aspects of life, relationships play a large role in the success of students with disabilities in college. Research indicates that students who have a strong support system with their peers are more likely to be successful and have a more positive social and academic adjustment in college. Students can receive support from their peers in a variety of ways: social settings, tutoring, study groups, and peer mentoring. As students with disabilities receive social support, they are able to experience comfort, relaxation, and encouragement. In addition, they are able to learn how to interact appropriately with their peers, roommates, and friends in college (Fleming et al., 2017). Social supports for students with disabilities in college can foster academic success (Fleming et al., 2017; Lombardi, Murray \& Kowitt, 2016).

In addition to peer relationships, the relationships between students with disabilities and faculty can have an impact on the student's success. It is important for students with disabilities to advocate for themselves. They need to be able to communicate what their disability is and how it impacts them. They can discuss their accommodations with the faculty so the faculty can provide one-on-one support. The students need to take it upon themselves to research the available resources within the college or university that can be used to increase their level of success (Fleming et al., 2017).

\section{THE SOCIALIZATION THEORY}

The socialization theory emphasizes the role of relationships in fostering success for students. Socialization refers to the process through which individuals acquire social skills, behavioral norms, and the values of the culture they are living in. The acquisition of these social skills makes it possible for the individual to become part of society. College students with disabilities need social understandings and emotional maturity skills to develop positive relationships with their peers and professors (Grusec \& Hastings, 2007).

Socialization occurs at different stages of development. The introduction to social skills for children starts with their families. As they grow older, they learn further social skills through their school, religious institutions, and eventually employment. The degree of social skills will vary as the child grows older and is exposed to more life experiences. This can become an issue for students with disabilities who may spend a significant amount of time with other children who have disabilities. They may not have the opportunity to learn appropriate age- and socially-acceptable social skills and behaviors from their peers because they were excluded from them in school or other settings (Grusec \& Hastings, 2007).

An important part of the socialization theory is emotional competence and the relation to social functioning. Emotional competence includes being able to express one's emotions and understand and empathize with the emotions of others. It also includes the ability to be able to regulate one's own emotions. Emotional competence can be difficult for students with disabilities to develop. A delay in these skills my become more of an issue for students as they go to college and are on their own, away from home for the first time (Grusec \& Hastings, 2007). Students with disabilities can still experience the negative effects of the stigma related to social marginalization. This can lead to a lack in confidence and communication skills (Palmer \& Roessler, 2000).

\section{PERCEPTIONS}

How students with disabilities in college are perceived may affect their relationships. Baker, Boland, \& Nowik (2012) found that how other students and faculty perceive students with disabilities can impact their academic success. 
Some faculty may not be knowledgeable regarding accommodations for students with disabilities, disability law and appropriate strategies to support students with disabilities. In addition, faculty can still display a lack of sensitivity towards individuals with disabilities and hold preconceived stereotypes of them (Baker et al., 2012). This leads to students feeling that they cannot be successful and, therefore, they put forth less effort. Faculty who express low expectations of students with disabilities, make negative comments about their disability, or do not comply with approved accommodations, may discourage students with disabilities so they have a poor experience and feel that there is no reason to self-advocate for themselves (Fleming et al., 2017).

How students with disabilities in college perceive the faculty's knowledge regarding disability law and accommodations can impact their success. Students are hesitant to seek the support they need if they see a lack of knowledge regarding disabilities and accommodations in the faculty. Positive reactions from other students regarding the needs of students with disabilities can encourage them to actively pursue the support they need (Baker et al., 2012). Success and satisfaction in the college environment for students with disabilities is largely influenced by the perceptions of peers. Acceptance of differences and support from peers can lead to an increase in the success and satisfaction of students with disabilities in college (Baker et al., 2012).

\section{ACCOMMODATIONS}

Section 504 of The Rehabilitation Act of 1973 was the first law requiring postsecondary schools to provide accommodations for persons with disabilities. When the law was first passed it was not implemented in the majority of postsecondary institutions. This instigated litigation brought on by students with disabilities who were not receiving accommodations. The issues that were brought up led to further investigation and litigation and led to the ADA. With the passing of this law, teacher training began on college campuses, along with more formalized processes for providing accommodations (Disability of College Campuses, 2013).

A faculty member's willingness to provide accommodations for students with disabilities directly impacts their success. Faculty members are more likely to provide accommodations such as extended time for tests and assignments or recorded lecture notes, but there are some accommodations that they are less likely to provide such as alternate forms of an exam or assignment, lecture notes, or extra credit, or modifications in grading for spelling or grammar mistakes. Faculty tend to have a more negative attitude towards providing accommodations for students with psychiatric or attention disorders than those with physical or learning disabilities. Students with disabilities feel that they experience a positive classroom environment when they feel the faculty is willing to provide their needed accommodations; however, some faculty perceive accommodations as a burden or something that can decrease the quality of learning (Baker et al., 2012). Students with disabilities recognize that faculty lack knowledge of how a disability can impact a student and the purpose or need for the accommodations (Baker et al., 2012).

As students with disabilities transition from high school to college, they need to be knowledgeable of their disability and what accommodations they will need to be successful. This will involve advocating for themselves and being aware of what accommodations are available at the college level. Research has determined that college students with disabilities are often not aware of the accommodations available to them or how to ensure they are receiving them in accordance with their civil rights as a student with a disability. Students with disabilities are accustomed to being part of a special education program in high school where they are guided through everything. They are not always prepared for the procedures nor do they know their rights at the college level (BarnardBrak et al., 2009). they often lack the social skills needed to request from or negotiate with their professors regarding accommodations. Providing specific training for students in how to request accommodations and effectively communicate with their professors regarding needed accommodations would be very beneficial (Palmer \& Roessler, 2000).

Some students who have disabilities do not feel that they require specialized services at the college level because they no longer consider themselves as having a disability (Barnard-Brak et al., 2009). In addition, there are students who are aware they 
have a disability but choose not to disclose this information. Students with disabilities may not see or choose not to see that they have something in common with other students who have disabilities. They may not want to be categorized as disabled (Disability of College Campuses, 2013). Therefore, there are students in college classes with disabilities who are not receiving the proper supports because the college is not aware they are needed. There a variety of reasons why students choose not to pursue the needed accommodations: they do not want to carry the special education label from high school with them into college, they want to wait and see if they will experience difficulty in their courses, or they are embarrassed or anxious about asking for the accommodations. Students may also be afraid of retaliation from the professor if they pursue the accommodations they need (Disability of College Campuses, 2013). The number of students with disabilities who complete their degree program increases for those who request the needed accommodations (Barnard-Brak et al., 2009).

As students hesitate to request the accommodations they need to be successful, it is important for the college or university and professors to create an environment that makes the students comfortable to reach out for what they need. In addition, it is a requirement of the ADA that institutions provide accommodations. An environment that focuses on setting everyone up for success would include the appropriate accommodations for students with disabilities (Disability of College Campuses, 2013). Providing accommodations for students with disabilities and giving them the appropriate supports also follows under the categories of diversity and multiculturalism. These two categories are mostly included on college campuses; however, disability is often overlooked.

\section{CONCLUSION}

As the number of students with disabilities enrolling in college increases, colleges and universities need to be proactive in creating an environment that will allow them to be successful regardless of their disability. Students with disabilities need to be provided with opportunities to develop positive relationships with their peers and the faculty. This can help to alleviate some of the negative perceptions of them. In addition, the college or university and its faculty must be knowledgeable regarding disability law and accommodations. 


\section{REFERENCES}

Americans with Disabilities Act of 1990, 42 U.S.C. $\S 12101$ et seq. (1990).

Baker, K. Q., Boland, K., \& Nowik, C. M. (2012). A campus survey of faculty and student perceptions of persons with disabilities. Journal of Postsecondary Education \& Disability, 25(4), 309-329.

Barnard-Brak, L., Davis, T., Tate, A., \& Sulak, T. (2009). Attitudes as a predictor of college students requesting accommodations. Journal of Vocational Rehabilitation, 31(3), 189-198. doi:10.3233/JVR-2009-0488

Disability of College Campuses: An Overview. (2013). ASHE higher education report, 39(5), 31-48.

Grusec, J. E., \& Hastings, P. D. (2007). Handbook of socialization: Theory and research. New York, NY: Guilford Press.

Herts, K. L., Wallis, E., \& Maslow, G. (2014). College freshman with chronic illness: A comparison with healthy first year students. Journal of College Student Development, 55(5), 475-480. doi:10.1353/csd.2014.0052

Individuals with Disabilities Education Improvement Act, 20 U.S.C. $\S 1400$ et seq. (2004).

Fleming, A. R., Plotner, A. J., \& Oertle, K. M. (2017). College students with disabilities: The relationship between student characteristics, the academic environment, and performance. Journal of Postsecondary Education \& Disability, 30(3), 209-221.

Lee, B. A. (2014). Students with disabilities: Opportunities and challenges for colleges and universities. Change, 46(1), 40. doi:10.1080/00091383.2014.867212

Lombardi, A., Murray, C., \& Kowitt, J. (2016). Social support and academic success for college students with disabilities: Do relationship types matter? Journal of Vocational Rehabilitation, 44. 1-13. doi:10.3233/JVR-150776

National Center for Educational Statistics. (2015). Fast facts: Postsecondary students with disabilities. Author, Washington: DC.

Palmer, C., \& Roessler, R. T. (2000). Requesting classroom accommodations: Self-advocacy and conflict resolution training for college students with disabilities. Journal of Rehabilitation, 66, 38-43.

Section 504 of the Rehabilitation Act of 1973, 34 C.F.R. Part 104. (1973)

VESID. (2001). Postsecondary Education and Individuals with Disabilities: Recommendations to New York State for Strategies to Increase Access and Opportunity. Albany, NY: The Office of Vocational and Educational Services for Individuals with Disabilities (VESID). Retrieved from http:/l www.suny.edu/disabilities/taskforce/, 2000. 